\title{
Casuística de leishmaniosis visceral canina en ciudades de la Provincia de Corrientes (Argentina) donde se registraron casos humanos
}

\author{
Maidana, H.R..; Llano, E.G.. ${ }^{2}$ Báez, A.D. ${ }^{3}$; Cabrera, W.R. ${ }^{2}$; López, J.E. ${ }^{3}$ \\ Cátedras Clínica de Pequeños Animales 1 , Anatomía II $^{2}$ y Hospital de Clínicas ${ }^{3}$, Facultad de Ciencias \\ Veterinarias, Universidad Nacional del Nordeste, Sargento Cabral 2139, Corrientes (3400), Argentina. Tel. 03783 \\ 425753. E-mail: anato2@vet.unne.edu.ar.
}

\begin{abstract}
Resumen
Maidana, H.R.; Llano, E.G.; Báez, A.D.; Cabrera, W.R.; López, J.E.: Casuística de leishmaniosis visceral canina en ciudades de la Provincia de Corrientes (Argentina) donde se registraron casos humanos. Rev. vet. 22: 2, 144-146, 2011. El objetivo de esta comunicación fue confrontar la casuística de leishmaniosis visceral canina con los casos registrados en seres humanos en algunas localidades de la Provincia de Corrientes (Argentina), con miras a establecer algún patrón que opere como herramienta para futuros planes sanitarios orientados al control de esta zoonosis. Se utilizaron datos humanos de entidades sanitarias y se obtuvieron diagnósticos en caninos mediante métodos indirecto (Kalazar rK 39) y directo (observación microscópica del amastigote en muestra de médula ósea), para las ciudades de Ituzaingó, Virasoro, Santo Tomé y Corrientes (Capital). Los resultados indicaron una relación directamente proporcional entre la cantidad de casos humanos versus caninos, que debería ser corroborada en estudios ulteriores que incluyeran lapsos más prolongados y mayor número de muestras.
\end{abstract}

Palabras clave: ser humano, perro, leishmaniosis visceral, nordeste argentino.

\begin{abstract}
Maidana, H.R.; Llano, E.G.; Báez, A.D.; Cabrera, W.R.; López, J.E.: Canine visceral leishmaniosis casuistry in cities from Corrientes Province (Argentina) where human cases were previously registered. Rev. vet. 22: 2, 144-146, 2011. The objective of this communication was to confront the casuistry of canine visceral leishmaniosis with human cases registered in some cities of Corrientes Province (Argentina), to determine the possible existence of a pattern that could be used as a tool for future sanitary strategies oriented to the control of this zoonotic disease. Human data of sanitary entities were used. Diagnosis in canines were performed by means of indirect (Kalazar rK 39) and direct (microscopic observation of the amastigote in bone marrow sample) methods, for the cities of Ituzaingó, Virasoro, Santo Tomé and Corrientes (Capital City). Results indicated a directly proportional relationship between the number of human versus canine cases, that should be corroborated in ulterior studies including larger trials and higher number of samples.
\end{abstract}

Key words: human being, dog, visceral leishmaniosis, northeast of Argentina.

\section{INTRODUCCIÓN}

La leishmaniosis visceral es una enfermedad reemergente y un problema creciente de salud pública a nivel mundial. Afecta a las personas y animales. $\mathrm{Su}$ agente etiológico es el parásito Leishmania chagasi, de la familia Trypanosomatidae, que se transmite por el vector Lutzomya longipalpis, pequeño flebótomo de 2-3 $\mathrm{mm}$. de longitud, que se encuentra en dispersión activa en el norte de Argentina, actualmente hasta el centro de la Provincia de Entre Ríos ${ }^{4,5}$.

Recibido: 4 agosto 2011 / Aceptado: 3 octubre 2011
El perro doméstico es considerado el reservorio principal de la leishmaniosis visceral urbana. Los animales afectados generalmente presentan una frondosa sintomatología clínica, pero en algunos casos son asintomáticos, lo cual genera marcadas dificultades diagnósticas ${ }^{5}$. No existe predilección por edad, raza o sexo de los animales involucrados, como así tampoco por la condición socioeconómica de los propietarios, aunque en nuestro país la mayoría de las veces se halla relacionada con los sectores marginales y carenciados de la población ${ }^{1}$.

La leishmaniosis visceral emerge por interacción entre reservorios, flebótomos y seres humanos. La pre- 
valencia de la enfermedad siempre es mayor en los perros que en las personas y usualmente el brote canino precede al de los seres humanos ${ }^{4}$. Para arribar al diagnóstico es imperioso realizar una minuciosa exploración del paciente. El diagnóstico de leishmaniosis visceral es difícil, debido a que en caninos los síntomas son muy variables y pueden ser semejantes a los de otras enfermedades ${ }^{2,3}$.

La presunción del diagnóstico clínico se confirma utilizando métodos complementarios, ya sean indirectos como el test rápido inmunocromatográfico Kalazar Detect Canine (rK 39) con sensibilidad de 80-97\%, ELISA, aglutinación directa (DAT), inmunofluorescencia indirecta (IFI), Western Blot e IDRM, o directos, a través de la observación microscópica del parásito en muestras obtenidas por punción de médula ósea (sensibilidad de 60-80\%), nódulo linfático (40-60\%), piel $(40 \%)$ y bazo $(96 \%)$. También pueden utilizarse: PCR (90-100\% de sensibilidad), cultivos in vivo e in vitro, xenodiagnóstico, inmunohistoquímica y estudios post mortem (histopatología) ${ }^{4}$.

El objetivo del trabajo fue comparar, para las localidades de Santo Tomé, Ituzaingó, Virasoro y Corrientes, la casuística de leishmaniosis visceral canina versus los casos detectados en personas, en búsqueda de alguna relación que pudiera utilizarse como herramienta para futuros planes sanitarios orientados al control de esta zoonosis.

\section{MATERIAL Y MÉTODOS}

La casuística humana fue tomada de los registros que los organismos sanitarios obtuvieron en el bienio 2010-2011. La casuística canina obtenida por nuestro grupo de trabajo incluyó 40 caninos de la ciudad de Ituzaingó, 40 de Virasoro y 156 de Corrientes (Capital). A ellos se le agregaron datos obtenidos de otras fuentes para la ciudad de Santo Tomé, donde se muestrearon 237 perros.

Cada perro fue sometido a extracción de sangre entera de la vena cefálica antibraquial y toma de muestras de médula ósea del extremo distal de la penúltima costilla, material que fue procesado en el Servicio de

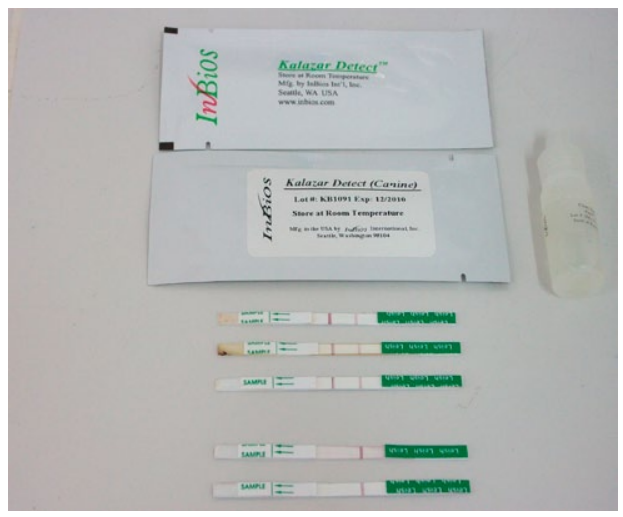

Figura 1. Método indirecto.
Diagnóstico de Leishmaniosis del Hospital de Clínicas de la Facultad de Ciencias Veterinarias de la UNNE, mediante métodos indirecto (test rápido inmunocromatográfico Kalazar Detect Canine rK 39, Figura 1) y directo (parasitológico, por observación microscópica del amastigote en muestra de médula ósea, Figura 2).

\section{RESULTADOS Y DISCUSIÓN}

Humanos. Los registros indicaron que en Virasoro solamente se registró un caso humano en el año 2009. En Ituzaingó fue detectado un caso en 2011. En Santo Tomé se produjeron 6 casos en 2010 y un caso en 2011. Para el período considerado, en Corrientes (Capital) no se registró ningún caso de leishmaniosis humana.

Caninos. En la ciudad de Virasoro a principio del año 2011 se detectó, utilizando métodos indirecto y directo, una casuística canina del 27,5\%. En Ituzaingó, durante el año 2011 se registró un 37\% de animales positivos a los métodos indirecto y directo. En Santo Tomé, para el año 2010, el equipo de veterinarios municipales reportó una casuística del $36,6 \%$ sobre 237 perros muestreados, diagnosticados por el método indirecto. En la ciudad de Corrientes, desde febrero a fines de abril de 2011, utilizando los procedimientos indirecto y directo se determinó una casuística canina del 10\%.

La Tabla 1 resume las casuísticas canina y humana para su mejor visualización. Se desprende que existe una relación directamente proporcional entre la cantidad de casos humanos versus caninos, que debería ser corroborada en estudios ulteriores que incluyeran lapsos más prolongados y mayor número de muestras.

Prima facie, la tendencia indicaría que el mayor número de canes afectados se correspondería con los más elevados casos de leishmaniosis humana. Estos datos podrían ser de utilidad al momento de plantear progra-

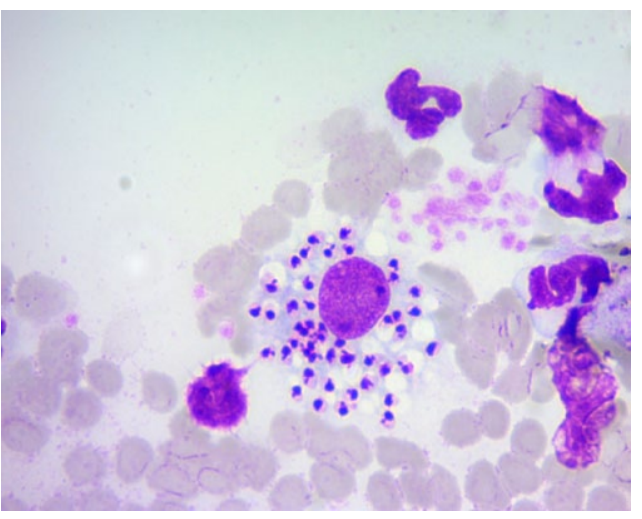

Figura 2. Método directo. 
mas de prevención, control y erradicación de la enfermedad $^{4}$, pues deberían incluir tanto aspectos médicos como veterinarios.

Agradecimiento. Al Méd. Vet. Juan Marelli, por aportar los datos correspondientes a los caninos de la ciudad de Santo Tomé.

\section{REFERENCIAS}

1. Borda CE, Rea MF, Rosa JR, Mosqueda LA. 1999. Leishmaniasis en la ciudad de Corrientes, Argentina. Memorias del XIV Congreso Latinoamericano de Parasitología, Acapulco, p. 14.

2. Fernández G, Maidana H, Pérez Valega E, Maccío O, Gorodner J. 2004. Examen parasitológico directo en el estudio de la leishmaniasis tegumentaria en animales y humanos descripción y análisis. Memorias Comunic Cientif Tecnol UNNE (Corrientes, Argentina), V-012.
3. Hommel M. 1978. The genus Leishmania: biology of the parasites and clinical aspects. Bull Instit Pasteur 75: 5-12.

4. Ministerio de Salud y Acción Social, Presidencia de la Nación. 2010. Leishmaniasis visceral, guía para el equipo de salud, Public. Dirección de Epidemiología, Buenos Aires, $52 \mathrm{p}$.

5. Salomón OD. 2010. Mapa de riesgo de leishmaniasis visceral en áreas vulnerables de Argentina y Uruguay, Publ. Programa Nacional de Leishmaniasis, Secretaría de Programas de Salud de la Nación Argentina, Buenos Aires, $144 \mathrm{p}$. 